\title{
Patients living with home enteral tube feeding: Side effects, health-related quality of life and nutritional care
}

\author{
Kaisa Bjuresäter, Maria Larsson, Elsy Athlin, Gun Nordström \\ Institution of Health Sciences, Department of Nursing, Karlstad University, Karlstad, Sweden
}

Correspondence: Kaisa Bjuresäter. Address: Institution of Health Sciences, Department of Nursing, Karlstad University, Universitetsgatan 1, S-651 88 Karlstad, Sweden. Email: kaisa.bjuresater@kau.se

Received: November 6, 2013

Accepted: April 30, 2014

Online Published: May 27, 2014

DOI : $10.5430 /$ cns.v2n3p64

URL: http://dx.doi.org/10.5430/cns.v2n3p64

\begin{abstract}
The aim of the study was to examine patients' perceptions of side effects, health-related quality of life (HRQL), general health, and nutritional care among patients receiving home enteral tube feeding (HETF) at two occasions after discharge from hospital. Three questionnaires, one study-specific, the Short Form 12 (SF-12) and the Health Index (HI), were sent to patients with HETF $(n=62)$ twice, two weeks after discharge from hospital and two months later. Forty patients responded two weeks after discharge and out of these 29 patients also responded after two months. Data were collected in central Sweden from March 2006 to January 2010. Side effects were common at both points of data collection (70\% of the patients after two weeks and $72 \%$ after two month). Patients using bolus feeding reported significantly fewer side effects than patients using intermittent feeding. HRQL and HI scores for the total group were low at both points of data collection. The bolus feeding group reported significantly higher physical HRQL and emotional HI than the intermittent feeding group did. Most patients were satisfied with the information and support they received from the health care team. This study has revealed that patients treated with HETF experienced side effects limiting their daily life to a great extent. Differences in HRQL related to feeding methods were found. Individualized support and regular controls are needed in order to meet patient needs. Bolus feeding may be a suitable feeding method to improve well-being.
\end{abstract}

\section{Key words}

Home enteral tube feeding, Side effects, Health-related quality of life, General health, Bolus feeding

\section{I ntroduction}

The number of patients receiving home enteral tube feeding (HETF) has rapidly increased both in the US and in Europe. Changes in equipment as well as in attitudes to tube feeding account for much of the growth ${ }^{[1,2]}$. An increased transfer of health care into the home environment has impacted the treatment of tube feeding as well ${ }^{[3,4]}$. Patients' training and adjustment to tube feeding is nowdays often taking place in the home environment due to shorter length of stay at hospital ${ }^{[5]}$, which puts a great responsibility on the patients and their families. Among patients with their cognitive function preserved, it is common that the patients, with or without help from their family, run daily care independently, but knowledge about their situation is still limited. 
Pros and cons for different routes for delivery of tube feeding, above all the use of nasogastric tube (NG) and percutaneous endoscopic gastrostomy (PEG), have been discussed in several studies ${ }^{[5-8]}$. PEG is a safe and comfortable method for long-term enteral feeding for appropriate patients according to guidelines from the European Society for Clinical Nutrition and Metabolism (ESPEN) ${ }^{[9]}$. Feeding methods for tube feeding have been described as intermittent feeding (given for a few hours three to four times during the course of the day ), continuous feeding (at all hours), or bolus feeding (given as a meal for 20-40 minutes using a syringe four to six times during the course of the day) ${ }^{[10]}$. Outcome measurements have been conducted in a small scale but sufficient scientific evidence is still lacking. No consensus is found in the literature about which feeding method is preferable and all are reported to have both advantages and disadvantages (e.g. time consumption, decreased mobility and disposition to aspiration) ${ }^{[11]}$. The use of bolus feeding has been questioned due to the risk of complications, but evidence for this is lacking ${ }^{[12]}$.

There are several gastrointestinal side effects such as flatulence, nausea, acid reflux, diarrhea and constipation associated with tube feeding which can be related to type of formula, feeding route and feeding methods ${ }^{[10,13]}$, but how these affect the patient's daily life is still scarcely described in the literature. Liley \& Manthorpe ${ }^{[14]}$ showed in a qualitative study that HETF treatment affected the daily life, and studies have shown that patients with HETF had poorer health-related quality of life (HRQL) compared to a normal population ${ }^{[3,4,15]}$. Only one longitudinal study ${ }^{[16]}$ has been found showing that HRQL improved over time. It is notable that several studies concerning HRQL for HETF patients have included patients both with and without cognitive impairments, and with caregivers responding to the questions when patients were unable to, which may compromise validity.

Accordingly, knowledge is scarce about how side effects and HRQL may change over time for this group of patients. Studies exploring general health and HRQL related to feeding methods or route of HETF are few. As treatment with HETF has increased rapidly in western countries, it is of great interest to further study side effects, HRQL and general health for these patients in order to meet their needs for nutritional care. The aim of this study was to examine patients' perceptions of side effects, HRQL, general health and nutritional care among patients receiving HETF at two occasions after discharge from hospital.

\section{Methods}

\subsection{Design}

The study design is longitudinal; patients' perceptions of side effects, health-related quality of life (HRQL), general health, and nutritional care among patients receiving home enteral tube feeding (HETF) were assessed at two occasions after discharge from hospital.

\subsection{Sample and procedure}

Patients treated with HETF delivered via NG or PEG including a low profile device were consecutively included from 28 units at ten hospitals in central Sweden, i.e. from all available hospitals and units in the area. Units for surgery, endoscopy, neurology, oncology and ear, nose and throat were chosen; in order to optimise the possibilities to obtain respondents, and consent to conduct the study was obtained from the respective Heads of the department. The data collection started at different time points, the first units started the data collection in March 2006 and the last unit completed their data collection in January 2010. Data were collected for two years from each unit. Inclusion criteria were patients 18 years or older, living in their own home, and able to read and write Swedish. The patients could run the tube feeding care independently, or with help from family or a health care team in the community. Exclusion criteria were patients with anorexia nervosa, aphasia or cognitive impairment. Nurses at the units asked patients fulfilling the inclusion criteria to participate in the study. All patients received both verbal and written information about the study from the nurses before consenting to participate about voluntary participation and confidentiality, and the opportunity to withdraw from the study 
whenever they wanted without any impact on their treatment or care. Two weeks after the patients' discharge from hospital, they were sent an invitation letter including information about the study and the first package of questionnaires. Responding to the questionnaires was taken as an informed consent. The second package of questionnaires was sent two months later, i.e. about ten weeks after discharge. Reminders were sent twice. Sixty-two patients agreed to participate, and 40 patients $(64 \%)$ responded to the questionnaires two weeks after discharge from the hospital. Out of these, 29 patients also responded on the second occasion for measurement.

\subsection{Questionnaires}

Three questionnaires were used: a study-specific questionnaire, the Short Form 12 (SF-12) and the Health Index (HI).

\subsubsection{Study-specific questionnaire}

Based on relevant literature and professional experience, a study-specific questionnaire was used. It included 31 questions about daily care of HETF, route of tube feeding, feeding methods, side effects related to tube feeding, contact with and support from the health care system and demographic data. Cronbach's alpha for this instrument was 0.83 . A pilot test of the questionnaire was performed before the data collection. Five nurse lecturers with clinical experience of nutritional care and tube feeding completed and commented on the questionnaire, resulting in minor adjustments (content validity). Thereafter, five patients with a history of HETF answered and commented on the revised questionnaire (face validity). No further adjustments were made. These five patients were not included in the main study.

\subsubsection{SF-12}

The generic health status instrument Short Form 12 (SF-12) was used to measure HRQL. The SF-12 contains eight scales concerning physical capacity, physical function, emotional function, pain, social functioning, vitality and perception of general and mental health, covering a physical component summary (PCS) and a mental component summary (MCS). The scale scores range from 0 to 100 , with 100 representing the highest level of physical and mental functioning ${ }^{[17]}$. In the general population the normed score is 50 with a standard deviation of 10 . Values between 47 and 53 are considered the average range for groups, with values below 47 indicating impairment ${ }^{[18]}$. Reference values have also been referred to scores of 40-47 indicating mild impairment, 30-39 indicating moderate impairment, and below 30 indicate severe impairment ${ }^{[17,19]}$. Reference values for a Swedish general population aged 60-64 years, which are comparable to the mean

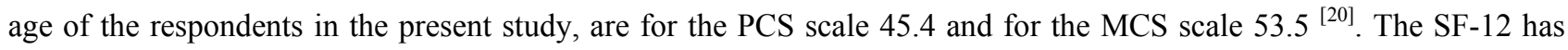
demonstrated good validity and reliability in previous studies ${ }^{[17,21,22]}$. In the present study, Cronbachs's alpha values for the scales ranged between 0.73 and 0.91 . The SF-12 was considered appropriate in this study where many patients are likely to have difficulty filling out a form that is too comprehensive.

\subsubsection{Health I ndex ( $\mathrm{HI})$}

The HI, measuring general health, was first published by Nordström et al. ${ }^{[23]}$ and is used in several studies ${ }^{[24-26]}$. Participants were asked to rate their health status during the previous week on a Likert-style scale ranging from 1 to 4 (very poor to very good) for each item. The scores are summarized into a Health Index ranging from 10 (the lowest self-rated health) to 40 (the highest self-rated health). Nordström et al. ${ }^{[23]}$ performed a factor analysis and defined two factors, emotional well-being (EWB) consisting of the items energy, temper, fatigue and loneliness, and physical well-being (PWB) consisting of the items mobility, sleep, vertigo, bowel function and pain. HI has been tested for reliability in

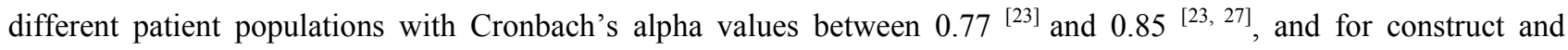
discriminant validity ${ }^{[23]}$. In this study, HI including 10 items can provide important information about the respondents' perceived health during the HETF treatment, and Cronbach's alpha in the present study was 0.80 .

\subsection{Data analysis}

For statistical analysis, the IBM SPSS 18 programs were used. SF-12 data was processed by means of a program provided by the HRQL group at the University of Gothenburg, Sweden ${ }^{[20]}$. To examine differences between two independent groups, the two-tailed Kolmogorov Smirnov Z test was used. Differences in proportions between two unrelated groups 
were tested using Pearson's Chi-square test (one degree of freedom) and in the case of small expected frequencies, the Fisher's Exact test. Odds ratio (OR) was calculated to measure the probability for differences in proportions between the unrelated groups. Wilcoxon signed-rank test was conducted to examine differences between two related groups. McNemar's test was used to test differences between two related groups concerning nominal data ${ }^{[28,29]}$. A significance level of 0.05 was utilized.

\subsection{Ethical approval}

The study was approved by the local Ethical Review Committee at Karlstad University, Sweden (no. C2006/33) and was carried out in accordance with Ethical guidelines for nursing research in the Nordic countries ${ }^{[30]}$ and the Declaration of Helsinki - Ethical Principles for Medical Research ${ }^{[31]}$. This means that the respondents were informed about the aim and design of the study, voluntary participation and confidentiality, and the opportunity to withdraw from the study whenever they wanted without any impact on their treatment or care. As patients treated with HETF may be weak and in a vulnerable situation, registered nurses at the units served as gate keepers, and assessed whether the patient was suitable to include in the study or not. Patients considered too weak or fragile were not asked for participation at all.

\section{Results}

\subsection{Patient characteristics}

The mean age of the respondents $(\mathrm{n}=40)$ was 63 years (range 30-86 years). Twenty-nine of them also responded to the questionnaires two months later, i.e. ten weeks after discharge (mean age 63 years, range 30-86 years). Characteristics are further presented in Table 1. Mean age for the 22 non-responding patients was 68 years (range $48-90$ years). There were no statistically significant differences between the non-responding patients and the responding patients concerning age, gender, or disease.

The indication for the HETF treatment was persistent dysphagia due to the patients' disease. For the patients with head and neck cancer, the dysphagia could also be a consequence of their treatment. The types of enteral formulas used were a standard-intact formula ( $38 \%$ of the patients, $\mathrm{n}=15)$, a fiber-enriched formula $(40 \%, \mathrm{n}=16)$, high-energy formula $(35 \%$, $\mathrm{n}=14)$, and other kinds of formulas $(20 \%, \mathrm{n}=8)$. Thirteen patients used a combination of two formulas. More than half of the patients used a PEG $(60 \%, \mathrm{n}=24)$ and the remaining used a NG. The patients were fed via intermittent feeding, with an infusion pump or with a gravity-controlled drip $(n=22)$, or given by a syringe as bolus feeding $(n=18)$. No patients were given the formula continuously at all hours. The amount of formula given each day to the responding patients varied between 500-3000 milliliters (mean $1345 \mathrm{ml}$; median $1500 \mathrm{ml}$, total group $(\mathrm{n}=40)$. Daily mean intake for the intermittent feeding group was $1525 \mathrm{ml}$ (median $1500 \mathrm{ml}$ ) and for the bolus feeding group the daily mean intake was $1120 \mathrm{ml}$ (median $1000 \mathrm{ml}$ ) (ns). The choice of feeding regime was based on the patients' individual needs and was decided by the responsible physician $(75 \%, \mathrm{n}=30)$ or by a dietitian or a nurse $(20 \%, \mathrm{n}=8)$.

\subsection{Side effects related to HETF}

Side effects related to HETF were common two weeks after discharge. Twenty-eight of the 40 patients (70\%) reported one or more side effects which they related to the tube feeding. Forty-eight percent $(n=19)$ of the patients reported one or two side effects, and the remaining patients $(22 \%, n=9)$ reported three to nine side effects. Flatulence and diarrhea were the most commonly reported side effects after two weeks (see Table 2). When comparing route of HETF (i.e. PEG and NG), no statistically significant differences in frequency of side effects were seen. Patients using intermittent feeding, significantly more frequently reported diarrhea and acid reflux compared to the bolus feeding group. The patients suffering from at least one side effect two weeks after discharge had a mean daily intake of feeding formula of $1285 \mathrm{ml}$ per day (range 500-2000 ml), while the twelve patients without any side effects had a mean intake of $1375 \mathrm{ml}$ per day $(p=1.000)$. Eighty-three percent of the patients $(n=23)$ consumed their prescribed tube feeding formula every day despite the experienced side effects. 
At the second point of measurement, side effects continued to be common among the 29 remaining respondents. The most common side effects after two months were flatulence $(34 \%, n=10)$, rumbling stomach $(28 \%, n=8)$, diarrhea $(24 \%, n=7)$, acid reflux $(24 \%, n=7)$, nausea $(24 \%, n=7)$, and constipation $(21 \%, n=6)$, not shown in the table. No statistically significant differences were found between the two occasions for measurement concerning frequency of side effects. When comparing route of HETF (i.e. PEG and NG) after two months, no statistically significant differences were found. However, when comparing feeding methods after two months, the patients fed with intermittent feeding more frequently reported early satiety $(36 \%, \mathrm{n}=5$ vs $0 \% ; p=0.017)$ and rumbling stomach $(29 \%, \mathrm{n}=4$ vs $0 \% ; p=0.042)$ than the bolus fed patients.

Table 1. Characteristics of patients treated with home enteral tube feeding (HETF) two weeks after discharge $(n=40)$ and two months thereafter, i.e. ten weeks after discharge $(n=29)$

\begin{tabular}{|c|c|}
\hline Two weeks after disc & Ten weeks after disch \\
\hline$n=40 \quad(\%)$ & $n=29$ \\
\hline
\end{tabular}

\section{Gender}

Males

25

(62)

19

Females

15

10

Civil status

Married/cohabitor

Living alone

Indication for HETF

Head and neck cancer

Amyotrophic lateral sclerosis (ALS)

Neurological disease

Crohn's disease

Other gastrointestinal disease

Route of HETF

Percutaneous endoscopic gastrostomy (PEG)

Nasogastric tube (NG)

Feeding method

\section{Bolus feeding ${ }^{\#}$}

Intermittent feeding via a gravity-controlled drip

Intermittent feeding using an infusion pump

$\begin{array}{lll}31 & (78) & 23 \\ 9 & (22) & 6\end{array}$

(17)

23

(1)

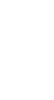

$\begin{array}{ll}19 & (65) \\ 6 & (21) \\ 2 & (7) \\ 1 & (3.5) \\ 1 & (3.5)\end{array}$

$\begin{array}{lll}18 & (45) & 15 \\ 15 & (38) & 10 \\ 7 & (17) & 4\end{array}$

\# given as a meal for 20-40 minutes using a syringe four to six times during the course of the day

\subsection{Health-related quality of life and general health}

Health-related quality of life (HRQL) and general health were examined for all patients responding two weeks after discharge $(n=40)$ and for those who responded both after two weeks and after two months (n=29) (see Table 3). No statistically significant differences were seen with regard to mean values for HRQL and general health between the two points of measurements $(n=29)$.

When comparing HRQL for the groups of patients using intermittent feeding and bolus feeding, the intermittent feeding group ( $\mathrm{n}=22$ ) reported significantly lower scores on physical HRQL (PCS 30.1) two weeks after discharge than the bolus feeding group $(\mathrm{n}=18$, PCS 34.7) $(p=0.026)$. The same pattern was also found after two months (PCS 31.6 vs 38.2; 
$p=0.044$ ). As regards route of tube feeding (PEG vs NG), no statistically significant differences were found. When comparing general health with regard to feeding method, the intermittent feeding group $(\mathrm{n}=22)$ reported significantly lower emotional health two weeks after discharge than the bolus feeding group $(\mathrm{n}=18)$ (EWB 9.0 vs 10.6; $p=0.022)$. After two months, there were no statistically significant differences in general health with regards to feeding methods or route of HETF (PEG and NG).

Table 2. Self-reported side effects related to home enteral tube feeding (HETF) for the total group and related to route of tube feeding and feeding methods two weeks after discharge $(\mathrm{n}=40)$

\begin{tabular}{|c|c|c|c|c|c|c|c|c|c|c|c|c|}
\hline & $\begin{array}{l}\text { Total } \\
n=40\end{array}$ & $\begin{array}{l}\text { group } \\
(\%)\end{array}$ & $\begin{array}{l}\text { PEG }^{\#} \\
\mathbf{n}=24\end{array}$ & $(\%)$ & $\begin{array}{l}N G^{\mathfrak{E}} \\
n=16\end{array}$ & $(\%)$ & $P$-value & $\begin{array}{l}\text { Inter } \\
\text { feedir } \\
\mathbf{n}=\mathbf{2 2}\end{array}$ & $\begin{array}{l}\text { ttent } \\
\text { (\%) }\end{array}$ & $\begin{array}{l}\text { Bolus } \\
n=18\end{array}$ & $\begin{array}{l}\text { feeding }{ }^{\beta} \\
(\%)\end{array}$ & $P$-value \\
\hline Flatulence & 19 & (48) & 12 & $(50)$ & 7 & (44) & 0.755 & 9 & (41) & 10 & $(56)$ & 0.525 \\
\hline Diarrhea & 18 & (45) & 10 & $(42)$ & 8 & (50) & 0.748 & 14 & (64) & 4 & (22) & $0.012^{\pi}$ \\
\hline Constipation & 15 & (38) & 9 & (38) & 6 & (38) & 1.000 & 7 & (32) & 8 & (44) & 0.517 \\
\hline Early satiety & 14 & (35) & 10 & (42) & 4 & (25) & 0.329 & 9 & (41) & 5 & (28) & 0.510 \\
\hline Acid reflux & 14 & (35) & 7 & (29) & 7 & (44) & 0.500 & 11 & $(50)$ & 3 & (17) & $0.046^{\Omega}$ \\
\hline Nausea & 14 & (35) & 7 & (29) & 7 & (43) & 0.500 & 10 & (46) & 4 & (22) & 0.186 \\
\hline $\begin{array}{l}\text { Abdominal } \\
\text { pain }\end{array}$ & 13 & (33) & 9 & (38) & 4 & (25) & 0.503 & 9 & (41) & 5 & (28) & 0.312 \\
\hline $\begin{array}{l}\text { Rumbling } \\
\text { stomach }\end{array}$ & 13 & (33) & 7 & (29) & 6 & (38) & 0.733 & 8 & (36) & 5 & $(28)$ & 0.737 \\
\hline Heartburn & 10 & $(25)$ & 4 & (17) & 6 & (38) & 0.159 & 5 & (23) & 5 & (28) & 0.731 \\
\hline Vomiting & 10 & (25) & 4 & (17) & 2 & (13) & 1.000 & 5 & (23) & 1 & (6) & 0.197 \\
\hline
\end{tabular}

\# Percutaneous Endoscopic Gastrostomy (PEG)

${ }^{£}$ Nasogastric tube (NG)

${ }^{\epsilon}$ allocated in shorter or longer periods of time throughout the day using a an infusion pump or a gravity-controlled drip

${ }^{\beta}$ given as a meal for 20-40 minutes using a syringe

${ }^{\pi}$ OR 6.07

${ }^{\Omega}$ OR 5.00

Table 3. Mean values for the Short Form 12 (SF-12) and the Health Index (HI) for patients treated with home enteral tube feeding (HETF) two weeks after discharge $(\mathrm{n}=40)$ and for those responding at both two weeks after discharge and two months thereafter, i.e. ten weeks after discharge $(\mathrm{n}=29)$

\begin{tabular}{|c|c|c|c|c|c|c|c|}
\hline & $\begin{array}{l}\text { Two weeks after } \\
\text { discharge } \\
\text { Mean }\end{array}$ & (SD) & $\begin{array}{l}\text { Two weeks after } \\
\text { discharge } \\
\text { Mean }\end{array}$ & (SD) & $\begin{array}{l}\text { Ten weeks after } \\
\text { discharge } \\
\text { Mean }\end{array}$ & (SD) & $P$-value \\
\hline & SF-12 $(n=40)$ & & SF-12 (n=29) & & SF-12 $(n=29)$ & & \\
\hline $\mathrm{PCS}^{\#}$ & 33.0 & (7.8) & 32.5 & (7.7) & 35.0 & $(9.4)$ & 0.098 \\
\hline $\mathrm{MCS}^{\mathfrak{f}}$ & 39.8 & (12.4) & 38.6 & (11.9) & 40.7 & (11.1) & 0.469 \\
\hline & HI $\quad(n=40)$ & & HI $\quad(n=28)^{\pi}$ & & HI $\quad(n=28)^{\pi}$ & & \\
\hline HI total & 27.3 & (4.6) & 27.3 & (4.6) & 28.4 & (5.2) & 0.156 \\
\hline $\mathrm{EWB}^{\epsilon}$ & 9.8 & (2.0) & 9.8 & (2.0) & 10.3 & $(2.2)$ & 0.248 \\
\hline $\mathrm{PWB}^{\beta}$ & 14.8 & $(2.5)$ & 15.0 & (2.4) & 15.2 & $(2.5)$ & 0.598 \\
\hline
\end{tabular}

${ }^{*}$ Physical Component Summary (PCS)

${ }^{£}$ Mental Component Summary (MCS)

${ }^{€}$ Emotional Well-Being (EWB)

${ }^{\beta}$ Physical Well-Being (PWB)

${ }^{\pi} \mathrm{n}=28$ one questionnaire missing 


\subsection{Nutritional care and daily life}

All patients $(\mathrm{n}=40)$ started their treatment with tube feeding at the hospital. Choice of feeding method was mainly decided at the hospital and 34 patients (85\%) stated that they had participated in the decision. Thirty-five patients (88\%) considered that respect had been shown to their daily life and to their unique situation. Thirty-two patients $(80 \%)$ ran their daily care of HETF by themselves, while eight patients (20\%), all using PEG, received help from their cohabitant, an adult child or home health care services.

Table 4. Nutritional care and support from health care for patients treated with home enteral tube feeding (HETF) two weeks after discharge $(n=40)$ and for those responding at both two weeks after discharge and two months thereafter, i.e. ten weeks after discharge $(\mathrm{n}=29)$

\begin{tabular}{|c|c|c|c|c|c|c|}
\hline & \multicolumn{2}{|c|}{$\begin{array}{l}\text { Two weeks after } \\
\text { discharge }(n=40)\end{array}$} & \multicolumn{2}{|c|}{$\begin{array}{l}\text { Two weeks after } \\
\text { discharge }(n=29)\end{array}$} & \multicolumn{2}{|c|}{$\begin{array}{l}\text { Ten weeks after } \\
\text { discharge }(=29)\end{array}$} \\
\hline & $\mathbf{n}$ & $(\%)$ & $\mathbf{n}$ & $(\%)$ & $\mathbf{n}$ & $(\%)$ \\
\hline $\begin{array}{l}\text { Knew how to handle practical } \\
\text { elements in daily care of HETF }\end{array}$ & & & & & & (86) \\
\hline Entirely & 33 & (83) & 24 & (83) & 25 & (10) \\
\hline To a moderately high extent & 5 & (13) & 5 & (17) & 3 & \\
\hline \multicolumn{7}{|c|}{$\begin{array}{l}\text { Care of HETF was handled in correct } \\
\text { and safely }\end{array}$} \\
\hline Entirely & 34 & (85) & 23 & (79) & 25 & (86) \\
\hline To a moderately high extent & 6 & (15) & 6 & (21) & 3 & (10) \\
\hline \multicolumn{7}{|l|}{ Felt safe with the HETF treatment } \\
\hline Entirely & 32 & (80) & 21 & (72) & 23 & (79) \\
\hline To a moderately high extent & 8 & (20) & 8 & (28) & 5 & (17) \\
\hline \multicolumn{7}{|l|}{ Received enough information } \\
\hline Entirely & 28 & (70) & 20 & (69) & 21 & (72) \\
\hline To a moderately high extent & 9 & (23) & 7 & (24) & 7 & (24) \\
\hline \multicolumn{7}{|c|}{$\begin{array}{l}\text { Received enough support from the } \\
\text { health care }\end{array}$} \\
\hline Entirely & 30 & (75) & 20 & (69) & 20 & (69) \\
\hline To a moderately high extent & 8 & (20) & 7 & (24) & 7 & (24) \\
\hline \multicolumn{7}{|c|}{$\begin{array}{l}\text { Knew where to turn to concerning } \\
\text { equipment }\end{array}$} \\
\hline Entirely & 32 & (80) & 23 & (79) & 24 & (83) \\
\hline To a moderately high extent & 6 & (15) & 5 & (17) & 2 & (7) \\
\hline \multicolumn{7}{|c|}{$\begin{array}{l}\text { Knew which one of the personnel who } \\
\text { was responsible for their HETF }\end{array}$} \\
\hline Entirely & 32 & (80) & 23 & (79) & 21 & (72) \\
\hline To a moderately high extent & 6 & (15) & 5 & (17) & 4 & (14) \\
\hline
\end{tabular}

Overall, two weeks after discharge, the majority of the patients reported that they received enough information and support from the health care team (see Table 4). Approximately one fifth of the patients reported that they had received enough information and support to a moderately high extent (see Table 4). Regarding daily life, 68\% ( $\mathrm{n}=27 / 40)$ of the patients stated that this functioned very well two weeks after discharge, while $52 \%(\mathrm{n}=15 / 29)$ stated that their daily life with HETF functioned very well two months after discharge. Eighteen patients (44\%) felt entirely restricted or restricted to a high 
extent in daily life due to HETF. Among those who felt restricted to some extent $(\mathrm{n}=33)$, reasons for this were: long time delivery of formula $(57 \%, n=19)$, hindered from participating in social events $(27 \%, n=9)$, forced to stay at home $(24 \%$, $\mathrm{n}=8)$ and decreased mobility $(18 \%, \mathrm{n}=6)$ (more than one alternative was possible). Fifty-nine percent $(\mathrm{n}=13)$ of the patients using intermittent feeding reported being restricted in their daily life, compared to $28 \%(\mathrm{n}=5)$ of the patients using bolus feeding who reported experiences of restrictions. After two months, $86 \%(\mathrm{n}=25)$ of the responding patients felt restricted to some extent due to HETF.

\section{Discussion}

Several studies concerning side effects and HRQL in relation to tube feeding in the hospital environment have been published earlier, but only a few studies have focused on these aspects in the home environment. This study contributes with new information about the patients' experiences of side effects over time, especially a higher frequency of self-reported diarrhea compared to other studies. It is important for health care personnel, both at hospital and in community care, to understand the nature and severity of patients' problems in the process of clinical decision making.

The patients' self-reported experiences are based on the issue of being treated with HETF, but whether their experiences of HRQL are connected to daily life with HETF, or to the fact that they were suffering from a severe disease, is of course difficult to know. In order to focus on their experiences of daily life with HETF, we have in the information letter to the patients and in the study-specific questionnaire asked them to report experiences or symptoms that they related to the tube feeding treatment. Data was collected by means of a SF-12, HI and study-specific questionnaire, which was developed from the literature and clinical experience with tube feeding both at hospital and in home care. The SF-12 and the HI had previously demonstrated both validity and reliability ${ }^{[17,21]}$. In this study the lowest Cronbach's alpha value was 0.73 , which may be considered as a limit value. However, it is comparable to previous studies and have been described as sufficient ${ }^{[29,32]}$. The study-specific questionnaire demonstrated content validity (nurse lecturers) and face validity (patients) in a pilot test. The HI instrument was chosen as it focuses on health rather than quality of life, and this broadens the picture gained from the SF-12. Lack of a systematic registration system regarding HETF-patients contributes to difficulties in identifying patients receiving HETF. Although several interventions to increase the number of included patients were performed, i.e. information and reminders to the recruiting nurses, the final number of respondents in the study sample was 40 at first occasion and 29 at second occasion. The generalizability of the findings is of course limited due to the rather small sample size. All subgroup analyses have been performed on a limited number of patients and the findings must be interpreted with caution. In relation to this there is also a risk for Type II errors ${ }^{[28]}$, since there may be actual differences between the subgroups which not have been shown in this study due to the small sample size. In future studies, data from a larger sample would provide more generalizable findings. Time for including patients at each unit was limited to two years in order to not burden the recruiting nurses. The total period of data collection can be considered as long, but no changes in the care or in local routines were done during this period. However, we consider the number of participants in the present study to be acceptable, as our numbers of respondents are similar or higher compared to other studies in the area ${ }^{[3,5,13,33]}$. For the 22 patients who did not respond to the questionnaires, the discharging units were contacted in order to obtain information about these patients. Eighteen of these patients were too weak to answer the questionnaires, and four patients had died in the two weeks period since discharge. The group of non-responding patients did not differ from the responding group with regard to age, gender or disease, which strengthens our findings.

Notable findings in our study were that many patients reported a high frequency of side effects. As the focus of this study was to examine patients' perceptions of their tube feeding treatment, the cause of the side effects was not examined. However, it is important to keep in mind that the patients themselves connected the experienced side effects to their tube feeding.

The patients related the experienced problems and inconveniences to their tube feeding. The most commonly reported side effects were flatulence, diarrhea and constipation which is an important knowledge in nursing. Diarrhea associated with 
tube feeding has mostly been studied in intensive care units and in hospital wards ${ }^{[34,35]}$, but is less frequently studied with regard to HETF. It is notable that the frequency of diarrhea in our study was high compared to other studies regarding patients treated with long-term $\operatorname{HETF}^{[5,13,36]}$. Studies with repeated measurements over time concerning side effects for patients treated with HETF are rare. The only study found ${ }^{[16]}$ with a similar focus as in our study showed that physical side effects such as nausea, acid reflux and diarrhea remained unchanged for the patients from one week to one month after discharge from hospital, which is in accordance with our findings. The limited research about side effects over time indicates that more evidence is needed to support interventions that will reduce side effects for long-term tube feeding in the home environment ${ }^{[5]}$.

An interesting finding was that the group of patients fed via intermittent feeding significantly more frequently reported diarrhea and acid reflux than the bolus feeding group, which should be considered when choosing feeding methods for patients in the home environment. Tube feeding methods have been studied and compared in several studies, mostly for patients in a hospital setting ${ }^{[37,38]}$ and in healthy volunteers ${ }^{[12,39]}$. These studies have mainly focused on diarrhea and appetite, and no consensus has been reached about one preferable method. However, Shang et al. ${ }^{[40]}$ compared pump-assisted versus gravity-controlled intermittent feeding among long-term PEG patients in home care, and they found significantly lower rates of diarrhea and flatulence in the pump-assisted group. There is a need to further evaluate feeding methods in the home environment since the circumstances at home are different in comparison to hospital care. Patients and relatives who run the daily care on their own may have difficulties both to assess and know how to deal with complications that arise. It is therefore important to monitor patients receiving HETF for a longer period of time after discharge in order to identify side effects or any complications. Registered nurses in community care or in home care teams play an important role in this monitoring. Furthermore, both before and after discharge patients need preparation and extended counselling about adequate interventions to decrease side effects and to increase the patients' well-being.

Quality of life has become a major concern for patients in need of long-term care. The patients in the present study reported low physical as well as mental HRQL two weeks after discharge. The physical component (PCS) showed lower scores (33.0) than the mental component (MCS) (39.8) but both values were below 47, which is considered as a significant impairment ${ }^{[18]}$. Of the four domains making up the PCS score, the Physical Functioning (PF) was most influential, and for the MCS score the domain Social Functioning (SF) was most influential. Our values were also low when comparing with a general population for the same age group ${ }^{[20]}$. Our results are also in line with the results reported by Jordan \& Philpin ${ }^{[33]}$ who studied patients treated with long-term PEG using the SF-12. Low HRQL values were also seen among our patients at the second point of measurement, after two months, a result in accordance with Schneider et al. ${ }^{[3]}$, who concluded that HRQL for patients treated with HETF longer than two months was poor. Also other groups of patients with long-term illnesses, e.g. stroke patients ${ }^{[22]}$, patients with advanced lung-, breast- and gastrointestinal cancer ${ }^{[19]}$, have reported low HRQL. This indicates that long-term care per se affects HRQL. Not surprisingly the general health of the patients in our study was also reported to be low. To be treated with long-term care in the home environment can be experienced as a relief since the patients can stay at home, with greater possibilities to live a normal life ${ }^{[41]}$. However, this has also been reported as being a burden ${ }^{[33,41]}$. Most patients considered that they had received enough information and support, but a number of patients had only received information and support to a moderately high extent, which indicates that they were lacking some information regarding the practical care of tube feeding. Since most patients ran their daily care of HETF by themselves, this may have affected the safety of the care. However, all patients stated that their daily life with HETF worked well two weeks after discharge. Despite this, they reported a low HRQL and low general health. These results may be related to the experience of being restricted in daily life. About two thirds of the patients experienced their lives as being restricted to various extents due to the long period of delivery of formula and restrictions in mobility and social life. One way to limit these restrictions could be a more frequent use of bolus feeding, which reduces the restricted time and improves the opportunity to live as normal as possible.

The use of bolus feeding has been questioned in previous research related to risk of complications, especially in recent years ${ }^{[12]}$. In the present study, about half of the patients used bolus feeding at both time periods. The patients using bolus 
feeding reported fewer side effects of diarrhea and acid reflux (two weeks after discharge), and early satiety and rumbling stomach (after two months) than the patients fed via intermittent feeding. The bolus-fed patients also reported higher physical HRQL and emotional health than the intermittent fed patients. These results may indicate the benefits of an increased use of bolus feeding for HETF patients with preserved cognitive function. This is also in line with results presented in a review by Raykher where the authors expressed bolus feeding as a preferable feeding method for patients who tolerates this method ${ }^{[42]}$. However, randomised controlled studies are needed to evaluate which type of feeding method is preferable. In the debate about the use of bolus feeding, it is important to stress the imperative need to identify the right patients without medical obstacles for bolus feeding to avoid complications. However, there may be several patients in health care who do not have medical obstacles for bolus feeding, but who for various reasons are never introduced to bolus feeding. One explanation for this may be lack of knowledge among health care personnel, both at hospitals and in home care. Bjuresäter et al. ${ }^{[43]}$ showed that district nurses in home care and district health care were uncertain about the management of tube feeding and experienced limited knowledge in the area. Thus there is a need to improve and update their knowledge about nutritional support ${ }^{[44]}$ including tube feeding. This would suggest that health care personnel should more often consider choosing bolus feeding as a suitable method for patients identified as appropriate.

\section{Conclusion}

To summarize, the contribution of this study is valuable since research about side effects and HRQL over time for HETF patients is scarce. An interesting finding was the fact that many patients reported a high frequency of different side effects, reported low HRQL and low general health, two weeks after discharge from hospital as well as two months later. However, the majority were satisfied with the support they received from the health care team. As most side effects found usually are possible to relieve or even cure, it must be a task for registered nurses to discover side effects in time, as well as to identify what interventions should be used to help the patients improve their wellbeing.

\section{Acknowledgements}

We gratefully thank statistician Jari Appelgren for statistical advice, translator Ian Watering for linguistic revision and the County Council of Värmland for financial support.

\section{Declaration of interest}

The authors declared no conflict of interest.

\section{References}

[1] Van Gossum A. Home Enteral Nutrition. Epidemiology and Legislation in Europe. In Home Care Enteral Feeding. (Lochs, H. and Thomas, D. eds. ) S. Karger AG, Basel; 2005: 59-71. PMid:15818022 http://dx.doi.org/10.1159/000083275

[2] DeLegge MH. Home Enteral Nutrition. Demographics and Utilization in the United States. In Home Care Enteral Feeding (Lochs, H. and Thomas, D. eds.) S. Karger AG, Basel; 2005: 45-58. PMid:15818021 http://dx.doi.org/10.1159/000083274

[3] Schneider S, Pouget I, Staccini P, Rampal P, Hebuterne X. Quality of life in long-term home enteral nutrition patients. Clinical Nutrition. 2000; 19(1): 23-28. PMid:10700530 http://dx.doi.org/10.1054/clnu.1999.0068

[4] Elia M, Stratton R. A cost-utility analysis in patients receiving enteral tube feeding at home and in nursing homes. Clinical Nutrition. 2008; 27: 416-423. PMid:18417257 http://dx.doi.org/10.1016/j.clnu.2008.02.004

[5] Crosby J, Duerksen DR. A prospective study of tube- and feeding-related complications in patients receiving long-term home enteral nutrition. Journal of Parenteral \& Enteral Nutrition. 2007; 31(4): 274-277. http://dx.doi.org/10.1177/0148607107031004274

[6] Ehrsson Y, Langius-Eklöf A, Bark T, Laurell G. Percutaneous endoscopic gastrostomy (PEG) - a long-term follow-up study in head and neck cancer patients. Clinical Otolaryngology. 2004; 29: 740-746. PMid:15533171 http://dx.doi.org/10.1111/j.1365-2273.2004.00897.x

[7] Yokohama S, Aoshima M, Nakade Y, Shindo J, Maruyama J, Yoneda M. Investigation and prediction of enteral nutrition problems after percutaneous endoscopic gastrostomy. World Journal of Gastroenterology. 2009; 15(11): 1367-1372. PMid:19294767 http://dx.doi.org/10.3748/wjg.15.1367 
[8] Dwolatyzky T, Berezovski S, Friedmann R, Paz J, Clarfield A, Stessman J, Hamburger R, Jaul E, Friedlander Y, Rosin A, Sonnenblick M. A prospecticve comparison of the use of nasogastric and percutaneous endoscopic gastrostomy tubes for long-term enteral feeding in older people. Clinical Nutrition. 2001; 20(6): 535-540. PMid:11884002 http://dx.doi.org/10.1054/clnu.2001.0489

[9] Löser C, Aschl G, Hébuterne X, Mathus-Vliegen EMH, Muscaritoli M, Niv Y, Rollins H, Singer P, Skelly RH. ESPEN guidelines on artificial enteral nutrition - Percutaneous Endoscopic Gastrostomy (PEG). Clinical Nutrition. 2005; 24: 848-861. PMid:16261664 http://dx.doi.org/10.1016/j.clnu.2005.06.013

[10] Rolfes S, Pinna K, Whitney E. Understanding normal and clinical nutrition. Thomson Higher Education, Belmont; 2006. PMid:17052198

[11] DeLegge M. Home Enteral Nutrition. Journal of Parenteral and Enteral Nutrition. 2002; 26(5): S4-S7. PMid:12216720 http://dx.doi.org/10.1177/014860710202600503

[12] Bowling T, Cliff B, Wright J, Blackshaw E, Perkins A, Lobo D. The effects of bolus and continuous nasogastric feeding on gastro-oesophageal reflux and gastric emptying in healthy volunteers: A randomised three-way crossover pilot study. Clinical Nutrition. 2008; 27: 608-613. PMid:18513835 http://dx.doi.org/10.1016/j.clnu.2008.04.003

[13] Reddy P, Malone M. Cost and outcome analysis of home parenteral and enteral nutrition. Journal of Parenteral \& Enteral Nutrition. 1998; 22(5): 302-310. http://dx.doi.org/10.1177/0148607198022005302

[14] Liley A, Manthorpe J. The impact of home enteral tube feeding in everyday life: a qualitative study. Health \& Social Care in the Community. 2003; 11(5): 415-422. http://dx.doi.org/10.1046/j.1365-2524.2003.00444.x

[15] Malone M. Longitudinal assessment of outcome, health status and changes in lifestyle associated with long-term home parenteral and enteral nutrition. Journal of Parenteral \& Enteral Nutrition. 2002; 26: 164-168. http://dx.doi.org/10.1177/0148607102026003164

[16] Roberge C, Tran M, Massoud C, Poirée B, Duval N, Frout D, Malvy D, Joly F, Lebailly P, Henry-Amar M. Quality of life and home enteral tube feeding: a French prospective study with head and neck or oesophagal cancer. British Journal of Cancer. 2000; 82(2): 263-269. PMid:10646875

[17] Ware J, Kosinski M, Keller S. A 12-Item Short-Form Health Survey: Construction of Scales and Preliminary Tests of Reliability and Validity. Medical Care. 1996; 34(3): 220-233. PMid:8628042 http://dx.doi.org/10.1097/00005650-199603000-00003

[18] Quality Metric. User's Manual for the SF-36v2 Health Survey. 2009.

[19] Mystakidou K, Parpa E, Tsilika E, Gennatas C, Galanos A, Vlahos L. How is sleep quality affected by the psychological and symtom distress of advanced cancer patients? Palliative Medicine. 2009; 22: 46-53.

[20] Sullivan M, Karlsson J, Taft C. SF-12 Hälsoenkät. Svensk användarhandbok. (SF-12 Health Survey. Swedish manual). Gothenburg University and Sahlgrenska University Hospital: Gothenburg; 1997.

[21] Jenkinson C, Layte R. Development and testing of the UK SF-12 (Short Form survey). Journal of Health Services Research \& Policy. 1997; 2(1): 14-18. PMid:10180648

[22] Pickard A, Johnson J, Penn A, Lau F, Noseworthy T. Replicability of SF-36 summary scores by the SF-12 in stroke patients. Stroke. 1999; 30: 1213-1217. PMid:10356102 http://dx.doi.org/10.1161/01.STR.30.6.1213

[23] Nordström G, Nyman C, Theorell T. Psychosocial adjustment and general state of health in patients with ileal conduit urinary diversion. Scandinavian Journal of Urology and Nephrology. 1992; 26: 139-147. PMid:1626203

[24] Barthelsson C, Anderberg B, Ramel S, Björvell C, Gieseke K, Nordström G. Outpatients versus inpatient laparoscopic cholecystectomy: a prospective randomized of symptom occurrence, symptom distress and general state of health during the first post-operative week. Journal of Evaluation in Clinical Practice. 2008; 14: 577-584. PMid:18462280 http://dx.doi.org/10.1111/j.1365-2753.2007.00920.x

[25] Eriksson L, Nordström G, Berglund T, Sandström E. The health-related quality of life in a Swedish sample of HIV-infected persons. Journal of Advanced Nursing. 2000; 32(5): 1213-1223. PMid:11115007 http://dx.doi.org/10.1046/j.1365-2648.2000.01592.x

[26] Sjöström H, Langius-Eklöf A, Hjertberg R. Well-being and sense of coherence during pregnancy. Acta Obstetricia et Gynecologica Scandinavica. 2004; 83: 1112-1118. PMid:15548141 http://dx.doi.org/10.1080/j.0001-6349.2004.00153.x

[27] Forsberg C, Björvell H. Swedish population norms for the GHRI, HI and STAI-state. Quality of Life Research. 1993; 2: 349-356. PMid:8136800 http://dx.doi.org/10.1007/BF00449430

[28] Agresti A, Finlay B. Statistical Methods for the Social Sciences. Pearson Education International, New Jersey; 2009.

[29] Field A. Discovering statistics using SPSS. SAGE Publications, London; 2005.

[30] Northern Nurses' Federation. Ethical guidelines for nursing research in the Nordic Countries. Vård i Norden. 2003; 23(4): 1-5 (Supplement).

[31] WMA. Declaration of Helsinki - Ethical Principles for Medical Research Involving Human Subjects. 2013.

[32] Streiner D, Norman G. Health Measurement Scales-A Practical Guide to Their Development and Use. Oxford University Press, Oxford; 2008.

[33] Jordan S, Philpin S. Percutaneous endoscopic gastrostomies: the burden of treatment from a patient perspective. Journal of Advanced Nursing. 2006; 56(3): 270-281. PMid:17042806 http://dx.doi.org/10.1111/j.1365-2648.2006.04006.x

[34] Pancorbo-Hidalgo P, Garcia-Fernandez F, Ramirez-Perez C. Complications associated with enteral nutrition by nasogastric tube in an internal medicine unit. Journal of Clinical Nursing. 2001; 10(4): 482-490. PMid:11822496 http://dx.doi.org/10.1046/j.1365-2702.2001.00498.x

[35] Morgan LM, Dickerson RN, Alexander KH, Brown RO, Minard G. Factors causing interrupted delivery of enteral nutrition in trauma intensive care unit patients. Nutrition in Clinical Practice. 2004; 19(5): 511-517. PMid:16215147 http://dx.doi.org/10.1177/0115426504019005511 
[36] Schattner M, Barrera R, Nygard S, Scott F, Quesada O, Brown P, Shike M. Outcome of home enteral nutrition in patients with malignant dysphagia. Nutrition in Clinical Practice. 2001; 16: 292-295. http://dx.doi.org/10.1177/088453360101600506

[37] Ciocon J, Galindo-Ciocon D, Tiessen C, Galindo D. Continous compared with intermittent tube feeding in the elderly. Journal of Parenteral \& Enteral Nutrition. 1992; 16: 525-528. http://dx.doi.org/10.1177/0148607192016006525

[38] Shun Wah Lee J, Auyeung TW. A comparison of two feeding methods in the alleviation of diarrhoea in older tube-fed patients: a randomised controlled trial. Age and Ageing. 2003; 32(4): 388-393. http://dx.doi.org/10.1093/ageing/32.4.388

[39] Stratton R, Stubbs J, Elia M. Bolus tube feeding suppresses food intake and circulating ghrelin concentrations in healthy subjects in a short-term placebo-controlled trial. The American Journal of Clinical Nutrition. 2008; 88: 77-83. PMid:18614727

[40] Shang E, Geiger N, Sturm J, Post S. Pump-assisted versus gravity-controlled enteral nutrition in long-term percutaneous endoscopic gastrostomy patients: a prospective controlled trial Journal of Parenteral \& Enteral Nutrition. 2003; $27(3)$ : $216-219$.

[41] Wennman-Larsen A, Tishelman C. Advanced home care for cancer patients at the end of life: a qualitative study of hopes and expectations of family caregivers. Scandinavian Journal of Caring Sciences. 2002; 16: 240-247. http://dx.doi.org/10.1046/j.1471-6712.2002.00091.x

[42] Raykher A, Russo L, Schattner M, Schwartz L, Scott B, Shike M. Enteral nutrition support of head and neck cancer patients. Nutrition in Clinical Practice. 2007; 22: 68-73. PMid:17242458 http://dx.doi.org/10.1177/011542650702200168

[43] Bjuresäter K, Larsson M, Nordström G, Athlin E. Cooperation in the care for patients with home enteral tube feeding throughout the care trajectory: nurses' perspectives. Journal of Clinical Nursing. 2008; 17(22): 3021-3029. PMid:19034990 http://dx.doi.org/10.1111/j.1365-2702.2007.02181.x

[44] Arvanitakis M, Coppens P, Doughan L, van Gossum A. Nutrition in care homes and home care: Recommendations - a summary based on the report approved by the Council of Europe. Clinical Nutrition. 2009; 28: 492-496. PMid:19699562 http://dx.doi.org/10.1016/j.clnu.2009.07.011 